\title{
Plastome phylogenomics and historical biogeography of aquatic plant genus Hydrocharis (Hydrocharitaceae)
}

Zhi-Zhong Li ${ }^{1,2}$, Samuli Lehtonen ${ }^{3}$, Andrew W. Gichira ${ }^{1,2,4}$, Karina Martins ${ }^{5}$, Andrey Efremov ${ }^{6}$, Qing-Feng Wang ${ }^{2,4}$ and Jin-Ming Chen ${ }^{1,2^{*}}$

\begin{abstract}
Background: Hydrocharis L. and Limnobium Rich. are small aquatic genera, including three and two species, respectively. The taxonomic status, phylogenetic relationships and biogeographical history of these genera have remained unclear, owing to the lack of Central African endemic H. chevalieri from all previous studies. We sequenced and assembled plastomes of all three Hydrocharis species and Limnobium laevigatum to explore the phylogenetic and biogeographical history of these aquatic plants.

Results: All four newly generated plastomes were conserved in genome structure, gene content, and gene order. However, they differed in size, the number of repeat sequences, and inverted repeat borders. Our phylogenomic analyses recovered non-monophyletic Hydrocharis. The African species $\mathrm{H}$. chevalieri was fully supported as sister to the rest of the species, and L. laevigatum was nested in Hydrocharis as a sister to H. dubia. Hydrocharis-Limnobium initially diverged from the remaining genera at ca. 53.3 Ma, then began to diversify at ca. 30.9 Ma. The biogeographic analysis suggested that Hydrocharis probably originated in Europe and Central Africa.

Conclusion: Based on the phylogenetic results, morphological similarity and small size of the genera, the most reasonable taxonomic solution to the non-monophyly of Hydrocharis is to treat Limnobium as its synonym. The African endemic $\mathrm{H}$. chevalieri is fully supported as a sister to the remaining species. Hydrocharis mainly diversified in the Miocene, during which rapid climate change may have contributed to the speciation and extinctions. The American species of former Limnobium probably dispersed to America through the Bering Land Bridge during the Miocene.
\end{abstract}

Keywords: Limnobium, Plastome, Divergence time, Hydrocharis chevalieri

\section{Backgroud}

Hydrocharis L., an aquatic monocot genus, has a broad native distribution in tropical and temperate regions of the Old World [1]. As traditionally circumscribed, the genus comprises only three allopatric species: Hydrocharis chevalieri (De Wild.) Dandy, H. morsus-ranae L. and H. dubia (Blume) Backer. Among them, H. chevalieri

\footnotetext{
${ }^{*}$ Correspondence: jmchen@wbgcas.cn

${ }^{2}$ Center of Conservation Biology, Core Botanical Gardens, Chinese

Academy of Sciences, Wuhan 430074, China

Full list of author information is available at the end of the article
}

is only found in small sedge swamps or wetlands in central Africa [1,2]. It is easily distinguished from the other two species by unique morphological features, e.g., long and erect petioles and the number of primary veins $(>4)$ in leaf lamina [1]. In comparison, $H$. morsus-ranae and H. dubia are more widely distributed. The native range of the former covers West and North Eurasia, whereas the latter is natively distributed in Southeast Asia [1, 3]. Beyond their natural range, $H$. morsus-ranae and $H$. dubia have invaded Northeast America and Australia, respectively [3], and cause serious damage to the local 
environment [2]. However, due to the deterioration of the aquatic habitats resulting from human activities, $H$. morsus-ranae and $H$. dubia have been considered threatened in part of their native distributions [3]. Hydrocharis and the closely related Limnobium are unusual in Hydrocharitaceae by having aerial leaves only, and therefore are important for understanding the evolution of aquatic adaptations in the family $[1,4]$. Additionally, $H$. morsusranae has been shown to have the ability to accumulate heavy metal elements making it a possible bioindicator of tracing element pollution in freshwaters [5].

Since the taxonomic revision of the genus Hydrocharis by Cook and Lüönd [1], only a few studies have focused on the systematics and taxonomy of the genus. Chen et al. [4] reappraised the generic relationships of Hydrocharitaceae using eight genes representing nuclear, plastid, and mitochondria genomes. The genus Hydrocharis was resolved as monophyletic and highly supported sister of Limnobium, a genus with two currently accepted species [6]. In that study, both Limnobium species were sampled, but one of the Hydrocharis species remained unsampled. Similarly, Ross et al. [7] resolved Hydrocharis and Limnobium as sisters in a phylogenomic analysis of 83 plastid genes, but they only sampled one species of each genus. Bernardini and Lucchese [8] further studied the phylogeny of Hydrocharitaceae using a dataset of ITS and five plastid genes. In their study, the taxon sampling and results concerning Limnobium and Hydrocharis were comparable with Chen et al. [4]. They suggested that these two genera could be merged into a single genus. This has also been supported by morphologic evidence $[6,9,10]$ and recently Plant Gateway [11] concluded without further justification - that Limnobium is part of Hydrocharis. However, the systematic relationships of Hydrocharis and Limnobium remain unclear due to the lack of morphologically intermediate Central African endemic $H$. chevalieri from all previous studies.

Previous biogeographic analyses suggested that the most recent common ancestor (MRCA) of the Hydrocharis-Limnobium clade originated in the Oriental region approximately $15.9 \mathrm{Ma}$, and long distance dispersal (LDD) might contribute to its current distributions [4]. However, numerous fossils, including more than 10 Hydrocharis species, which mainly occurred during the Oligocene and Miocene epochs, were discovered in Europe and the Far East [3, 12-15]. No fossils have been found in Africa. The biogeographic history of the African species $H$. chevalieri has been unsolved, limiting a comprehensive understanding of the biogeographic history of the genus.

As the plastome has become more easily retrievable, it has dramatically enhanced the resolution of phylogenetic relationships at various taxonomic levels [7, 16-18].
Here, we sequenced and assembled plastomes of all three Hydrocharis species and Limnobium laevigatum. The objectives of this study were to 1 ) investigate the plastome evolution in this group; 2) clarify the phylogenetic relationships of Hydrocharis and Limnobium; and 3) infer the historical biogeography of the group.

\section{Results}

\section{Plastome feature}

After de novo assembly, we obtained the complete plastome of three Hydrocharis species and L. laevigatum from genome skimming data. The coverage of each plastome ranged from $\sim 807 \times$ to $\sim 878 \times$ (Table 1 ). The size of newly assembled plastomes ranged from $153,373 \mathrm{bp}$ to $159,698 \mathrm{bp}$ and exhibited the typical quadripartite structure (Fig. 1), including a pair of IRs $(22,292-$ $30,605 \mathrm{bp}$ ) separated by the Large Single Copy (LSC, 85,578-89,581 bp) and Small Single Copy (SSC, 11,27821,476bp) regions (Table 1). Except for rps16, lost from the plastome of $H$. chevalieri, the other plastomes encoded 113 unique genes, which is similar to most of the plastomes in angiosperms. Unique genes comprised 79 PCGs, 30 tRNA genes, and four rRNA genes. Both the average gene density $(\sim 0.8)$ and the overall GC content $(\sim 37 \%)$ of plastomes were conserved across the species. Furthermore, a small inversion of the trnN-GUU gene was detected in H. dubia plastome (Fig. 1).

\section{Comparison of border regions and sequence identity}

The IR/LSC and IR/SSC junctions were compared to assess the IR expansion or contraction of the plastome. Here, the LSC/IRa (JLA) and LSC/IRb (JLB) junctions were identical for all four species; IR expanded into the rpl23 gene at the JLB, and the JLA were located at the trnI-trnH intergenic spacer (Fig. 2). substantial divergence was detected at the SSC/IRa (JSA) and SSC/IRb (JSB) junctions. In $H$. dubia IR expanded into the $y c f 1$ gene at the JSA, whereas in $H$. chevalieri the $n d h A$ gene overlapped with the JSA and in $H$. morsus-ranae and $L$. laevigatum JSA was placed in $y c f 1$-trnN intergenic spacer. In comparison, at the JSB the IR regions expanded into genes in $H$. dubia (ycf1), H. morsus-ranae (ndhF) and L. laevigatum $(n d h F)$. The JSB of $H$. chevalieri lay in the $n d h H-n d h F$ intergenic spacer.

Both the sequence identity analysis and $\mathrm{Pi}$ values revealed a high differentiation among the newly assembled plastomes. The divergent regions were mostly derived from IGS regions (Fig. S1,S2), e.g., ycf1-trnNGUU, rps16-trnQ-UUG, trnI-CAU-ycf2, ycf2-trnI-CAU , trnK-UUU-rps16. Additionally, the top five PCGs, $y c f 1$, rps12, rps18, rps3, accD, showed relatively high nucleotide diversity and had the potential to be developed into molecular markers for further phylogenetic research. 
Table 1 Detailed information of the newly assembled plastomes

\begin{tabular}{lllll}
\hline Name of organism & Hydrocharis dubia & Hydrocharis chevalieri & $\begin{array}{l}\text { Hydrocharis } \\
\text { morsus-ranae }\end{array}$ & Limnobium laevigatum \\
\hline Voucher No. & HIB-LZZ-SB12 & HIB-LZZ-Cam19 & 14,513 & HIB-CJM-Bra50 \\
Collection Sites & China; Wuhan & Cameroon; Mangueme & - & Brazil; Rio de Janeiro \\
GenBank accession number & OK326868 & OK326871 & OK326869 & OK326870 \\
SRA accession number & SRR16469680 & SRR16469681 & SRR16469679 SRR16469678 \\
Raw data (G) & 8.5 & 7.7 & 8.5 & 7.4 \\
Clean data (G) & 8.2 & 7.5 & 8.1 & 7.2 \\
Mean coverage & $828 \times$ & $807 \times$ & $872 \times$ & $878 \times$ \\
Genome size (bp) & 159,698 & 158,066 & 153,881 & 153,373 \\
LSC length (bp) & 89,581 & 85,578 & 88,098 & 87,313 \\
SSC length (bp) & 18,211 & 11,278 & 20,695 & 21,476 \\
IR length (bp) & 25,953 & 30,605 & 22,544 & 22,292 \\
Number of genes & 113 & 112 & 113 & 113 \\
Number of protein-coding genes (duplicated in IR) & $79(4)$ & $78(6)$ & $79(3)$ & $79(3)$ \\
Number of tRNA genes (duplicated in IR) & $30(7)$ & $30(7)$ & $30(7)$ & $30(7)$ \\
Number of rRNA genes (duplicated in IR) & $4(4)$ & $4(4)$ & $4(4)$ & $4(4)$ \\
Number of genes with one intron (two introns) & $16(2)$ & $15(2)$ & $16(2)$ & $16(2)$ \\
Proportion of coding to non-coding regions & 0.73 & 0.74 & 0.82 & 0.72 \\
Average gene density (genes/kb) & 0.8 & 37 & 37.2 & 0.73 \\
GC content (\%) & 37.2 & & 0.83
\end{tabular}

\section{Sequence repeat and SSR analysis}

The SSR analysis revealed a similar number of SSRs (Table S1), ranged from 64 (H. morsus-ranae) to 69 (H. dubia), within Hydrocharis species. In contrast, a clearly higher number of SSRs was detected in L. laevigatum (85). Moreover, species of Hydrocharis had the largest number of tri-, tetra-, and hexa-nucleotide repeats, whereas L. laevigatum was rich in mono-, and di- nucleotide repeats were more common in L. laevigatum (Table S1). Four types of repeat elements, forward, palindromic, reverse, and complementary, were identified for Hydrocharis and L. laevigatum plastomes. The total number varied from 383 (H. morsus-ranae) to 689 ( $H$. dubia) repeats of $30-317 \mathrm{bp}$ length for the newly generated plastomes (Fig. S3). Forward repeats were the most common and complementary repeats were the rarest repeat type. Based on the repeat size, we further divided all repeats into the following categories: $35-45 \mathrm{bp}, 46-60 \mathrm{bp}$, $61-75 \mathrm{bp}, 76-90 \mathrm{bp}$, and $>90 \mathrm{bp}$ (Fig. 3). At least half of the repeats belonged to the size class of $35-45 \mathrm{bp}$, and the majority of long repeats ( $>90 \mathrm{bp}$ ) were located in the plastome of $H$. dubia (107 repeats).

\section{Phylogenetic analysis}

Both ML and BI methods, regardless of partitioning strategy, revealed completely identical topologies and robust support for most of the nodes (Fig. 3). Two major clades were identified with high support $(B S=99 / 100$, $\mathrm{PP}=1 / 1$ ) and the genus Stratiotes was fully resolved as the sister to these two clades. Hydrocharis and Limnobium were clustered with full support $(B S=100 / 100$, $\mathrm{PP}=1 / 1)$ and resolved as the sister group of the remaining genera within Clade I. However, Hydrocharis did not form a monophyletic group, but L. laevigatum was nested within it as a fully supported sister to $H$. dubia. Additionally, African species $H$. chevalieri was fully supported as sister to the rest of the species within (Hydrocharis + Limnobium) group, and H. morsus-ranae shared a common ancestor with (L. laevigatum $+H$. dubia).

\section{Divergence time estimation and biogeographical reconstruction}

The MRCA of Hydrocharitaceae was inferred at ca. 61.7 Ma [Fig. 3, 95\% highest posterior densities (HPD): $54.6-71.8 \mathrm{Ma}$ ] and the Clade I and Clade II split from each other at $57.6 \mathrm{Ma}$ (95\% HPD: 49.5-67.4Ma). In Clade I, Hydrocharis-Limnobium initially diverged from the remaining genera at ca. 53.3 Ma (95\% HPD: 43.763.1 Ma), and then began to diversify at ca. 30.9 Ma (HPD: 13.8-49.9 Ma). The MRCA of H. dubia and L. laevigatum was dated at ca. 12.84Ma (95\% HPD: 3.8-24.1 Ma) and diverged of $H$. morsus-ranae and the remaining species at ca. 17.5 Ma (95\% HPD: 6.6-30.5 Ma).

Biogeographical reconstruction was implemented using RASP [19] with DIVALIKE model supported as 


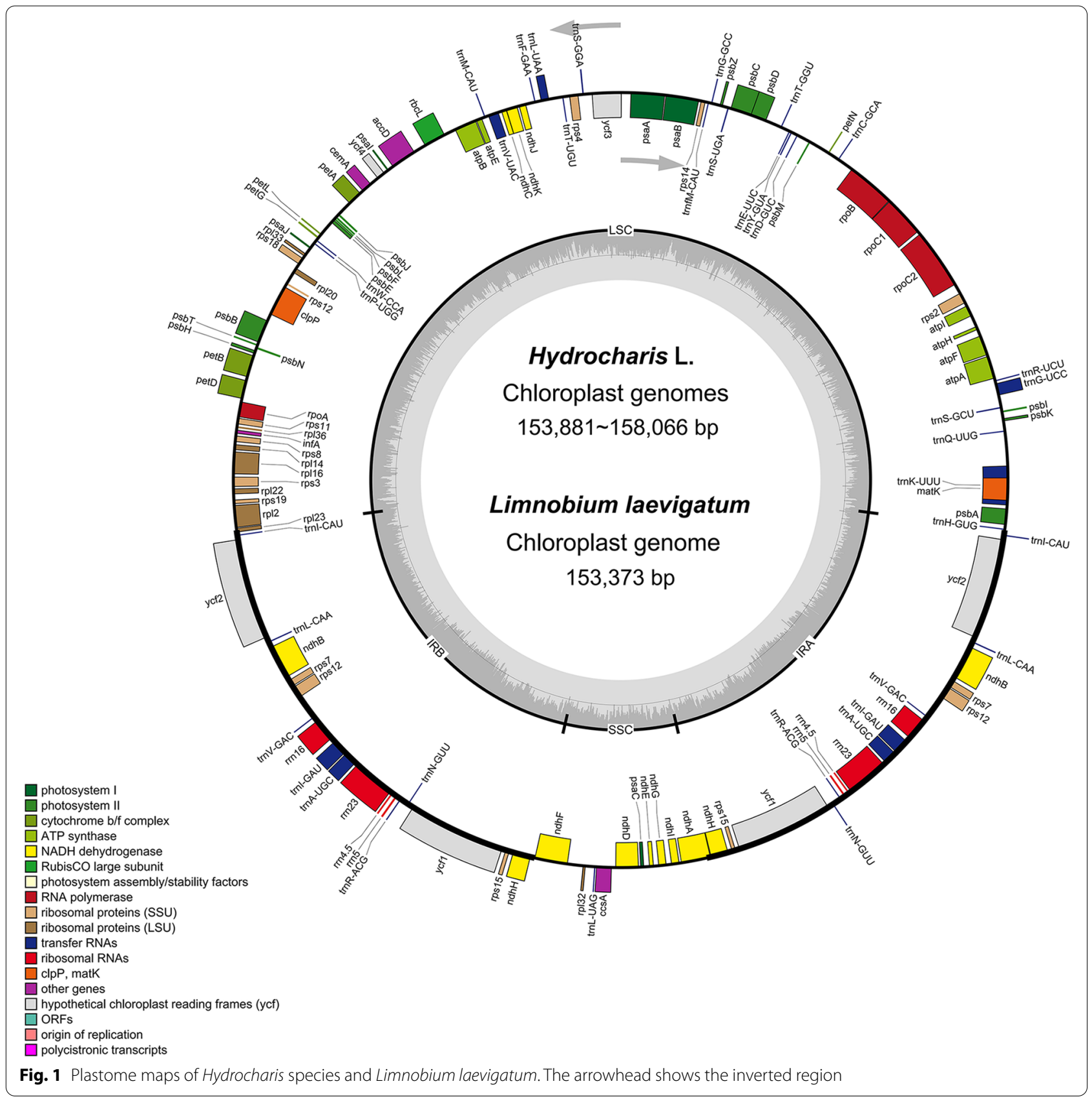

the best-fit model $(\mathrm{LnL}=-8.23$, AICc $=24.46$, AICc $\mathrm{wt}=0.56$; Table 2) from BioGeoBEARS analysis. However, the ancestral area remained uncertain. The scenario with the highest probability (39\%) suggested that the genus originated in Europe and Central Africa, followed by diversification due to three vicariance and two dispersal events (Fig. 3).

\section{Discussion}

\section{Plastome evolution}

Similar to the most reported plastomes of angiosperms $[17,20]$, all the plastomes in our study exhibited relatively conservative genome structure, gene content, and gene order [21, 22]. However, when compared to H. morsusranae and $L$. laevigatum, $H$. dubia $(159,698 \mathrm{bp})$ and $H$. chevalieri $(158,066 \mathrm{bp})$ had larger plastomes. One reason for plastome size variation is the expansion or contraction of IRs $[23,24]$. Indeed, $H$. dubia and $H$. chevalieri 


\section{Inverted Repeats}



Fig. 2 Comparison of the boundary of Hydrocharis species and Limnobium laevigatum

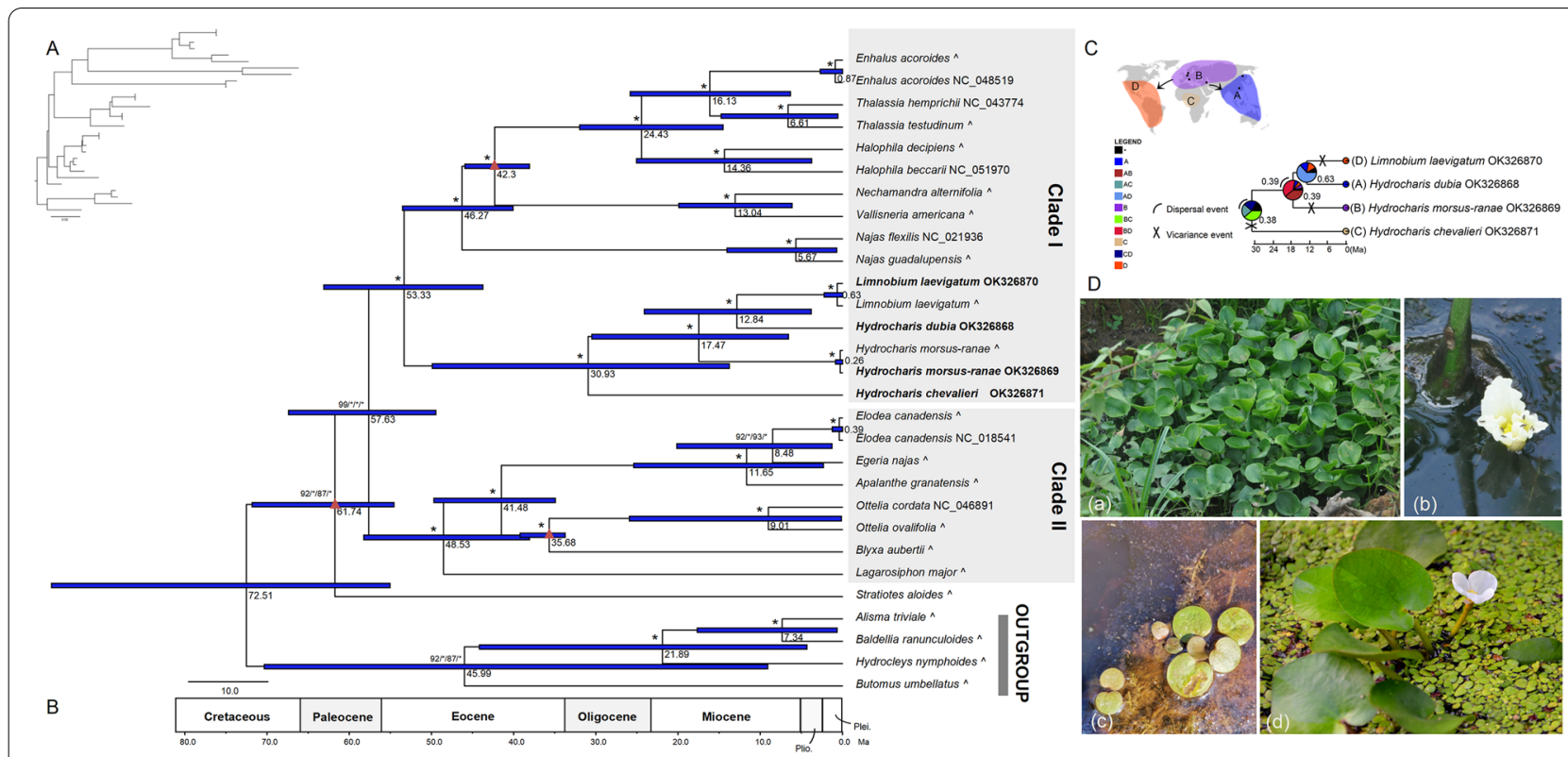

Fig. 3 Phylogenomic and biogeographic analysis of Hydrocharis. A the phylogenetic tree of Hydrocharitaceae was reconstructed from 78 PCGs sequences. B the dated phylogenetic tree of Hydrocharitaceae. Caret indicates the data downloaded from Ross et al. (2016). Asterisks represent bootstrap support $=100$ /posterior probability $=1.00$; the first two values represent unpartitioned data, and the last two values represent partitioned data. Triangles indicate the fossil calibration nodes and numbers below branches refer to the mean divergent time estimates. Error bars indicate $95 \%$ highest posterior distributions. C the biogeographic analysis of the genus Hydrocharis. The black points indicates the location of Hydrocharis fossils [3]. D Plant photos of Hydrocharis and Limnobium were taken by Zhi-Zhong Li. a-b, H. chevalieri; c, L. laevigatum; and d, H. dubia 
Table 2 Results of BioGEoBEARS models for the ancestral area reconstruction

\begin{tabular}{llllllll}
\hline Model & LnL & num params & $\mathbf{d}$ & $\mathbf{e}$ & $\mathbf{j}$ & AICc & AICc_wt \\
\hline DEC & -9.26 & 2 & 0.018 & 0.027 & 0 & 26.52 & 0.2 \\
DEC+J & -6.02 & 3 & $1.00 \mathrm{E}-12$ & $1.00 \mathrm{E}-12$ & 0.19 & 30.03 & 0.035 \\
DIVALIKE & $\mathbf{- 8 . 2 3}$ & $\mathbf{2}$ & $\mathbf{0 . 0 0 8}$ & $\mathbf{3 . 6 0 E - 0 5}$ & $\mathbf{0}$ & $\mathbf{2 4 . 4 6}$ & $\mathbf{0 . 5 6}$ \\
DIVALIKE+J & -5.28 & 3 & $1.00 \mathrm{E}-12$ & $1.00 \mathrm{E}-12$ & 0.15 & 28.56 & 0.072 \\
BAYAREALIKE & -9.82 & 2 & 0.027 & 0.047 & 0 & 27.65 & 0.11 \\
BAYAREALIKE+J & -6.66 & 3 & $1.00 \mathrm{E}-07$ & $1.00 \mathrm{E}-07$ & 0.2 & 31.32 \\
\hline
\end{tabular}

had one $(y c f 1)$ and three more genes $(y c f 1, \operatorname{rps} 15$, and $n d h H)$ in IRa, respectively, than the other two species. In addition, typical patterns of the plastome evolution associated with the fluctuation of plastome length include the gain/loss of genes, pseudogenization, and variations in intergenic regions [24-26]. Our results revealed the loss of gene rps16 in African endemic H. chevalieri. This gene has been reported missing from plastomes in many plant groups, e.g., Oxalidaceae [27, 28], Podostemaceae [29], and Violaceae [25]. It seems that rps 16 has been frequently transferred to the nuclear genome [20,30]. Additionally, a small inversion of the trnN-GUU gene near the IR boundary was detected in $H$. dubia. The inversion was likely related to the shift in the IR boundary (Fig. 2), as identified and demonstrated by Zhu et al. [31].

Previous studies $[4,8]$ have applied only five plastid genes ( $r b c L$, mat $K$, rpoB, rpoC1, trnK) to resolve the phylogeny with the genus Hydrocharis. However, there was only low nucleotide diversity $(\mathrm{Pi}<0.06)$ within these five genes, which might have affected the accuracy and resolution of phylogenetic reconstruction [32]. In our study, a number of regions (Fig. S2), including five plastid genes $(y c f 1, r p s 12, r p s 18, r p s 3, a c c D)$ and five intergenic spacers (ycf1-trnN-GUU, rps16-trnQ-UUG, trnI-CAU-ycf2, ycf2trnI-CAU, trnK-UUU-rps16), were detected as hotpots and may be helpful even in population genetic studies in the genus.

The high frequency of repeat sequences has been demonstrated to be one of the leading causes of plastome rearrangement and divergence [33]. Our analysis identified many repetitions ( $>350$ ) with more than 30 bp length in all newly assembled plastomes. Among these, short repeat sequences $(30-45 \mathrm{bp})$ were dominant, similar to other plant plastomes that have not undergone largescale structural variation. SSRs are widely distributed in plant plastomes and exhibit relatively high polymorphism, which can be used in population genetics [34-36]. The majority of SSRs were mono- and di- nucleotides in four newly assembled plastomes, which have been reported in other angiosperm plastomes, e.g., Primula [37], Dendrosenecio [18], and Oxalis [28]. The cpSSRs reported here could be used as genetic markers for future studies into the genetic diversity of Hydrocharis.

\section{Phylogeny and biogeographical reconstruction}

Prior to this study, no molecular information was available for the African endemic $H$. chevalieri. Here we have clarified the relationships within Hydrocharis by assembling and reporting the plastomes of all three Hydrocharis species and Limnobium laevigatum. Unlike previous studies [4, 8], H. morsus-ranae was fully supported (Fig. 3, $\mathrm{BS}=100 / 100 ; \mathrm{PP}=1 / 1$ ) as sister to the (L. laevigatum $+H$. dubia), instead of getting together with $H$. dubia, which was likely due to the inadequacy of L. spongia in our current study. Moreover, we recovered non-monophyletic Hydrocharis. The genus Limnobium represented here by L. laevigatum was nested in Hydrocharis as sister to H. dubia with robust support (Fig. 3, $\mathrm{BS}=100 / 100 ; \mathrm{PP}=1 / 1)$. This contradicting result might be because previous studies did not include $H$. chevalieri and used only a limited number of molecular markers $[4,8]$. Furthermore, a series of morphological features support the current phylogenomic relationships (Fig. 3). Vegetatively, Hydrocharis and Limnobium are indistinguishable, but $H$. chevalieri has stout, erect petioles, and laminas with a large number of primary veins, some of which originate from the lower half of the midrib [6]. The remaining species have slender petioles and primary veins originating from the point of petiolar attachment [6]. Limnobium differs from Hydrocharis by its rudimentary petals [6]. Given the morphological similarity and small size of the genera, only two species in Limnobium and three species in Hydrocharis, the most reasonable taxonomic solution to the non-monophyly of Hydrocharis is to treat Limnobium as the synonym of Hydrocharis. Nomenclatural combinations already exist, i.e., Hydrocharis spongia Bosc and Hydrocharis laevigata (Willd.) Byng \& Christenh.

Our time-calibrated tree indicated stem node age of about $53 \mathrm{Ma}$ for Hydrocharis (Fig. 3), which is similar to the previously reported median age of $54.7 \mathrm{Ma}$ [4] and in agreement with the oldest known Hydrocharis fossils 
from the Eocene [38]. The crown age of Hydrocharis was estimated to be approximately $31 \mathrm{Ma}$, much older than the 15.9 Ma reported in Chen et al. [4] based on analysis that lacked $H$. chevalieri, the sister species of the remaining genus. Based on our results, Hydrocharis mainly diversified in the Miocene, which is consistent with the time inferred for many other extant plant species [39, 40]. Rapid climate change during the Miocene may have contributed to the speciation of Hydrocharis as well as extinctions, given that the fossil diversity is high in comparison to the limited extant diversity [41, 42]. Additionally, paleoclimatic changes may have induced such changes in water bodies that some groups were driven to extinction [43]. This might explain why there are only three extant species, and a majority of fossil groups only occurred in Europe during the Miocene [3].

The area of origin remained uncertain for the genus because several alternative areas with low probabilities were recovered for the deeper nodes (Fig. 3). This may, of course, also reflect a widespread ancestral distribution. Although, L. spongia from America was not sampled here, our model with the highest probabilities for the ancestor of the genus in Europe, Central Asia, and Central African regions (Fig. 3) contrasted the biogeographical model of Chen et al. [4], which suggested origination in the Oriental area. Additionally, our results indicated that at least three vicariance and two dispersal events had shaped the current distribution of the genus (Fig. 3). One dispersal event was from Central Africa to Europe and Central Asia, probably via the last direct connection between Eurasia and Africa prior to the Miocene. The rapid climate change during the Miocene likely resulted in the isolation of $H$. chevalieri, as well as contributed to the extinction of many Hydrocharis species in Europe, as also proposed for Pyrularia [44], Allioideae [45] and some Compositae groups [46]. And other one dispersal route from Europe and Central Asia to America, East and Southeast Asia. The Bering Land Bridge (BLB) has been proved to play an important role in the dispersal of different plant lineages between Eurasia and America [47-49]. The former genus Limnobium, naturally recorded only in America, may have dispersed to America through the BLB during the Miocene $[49,50]$. The LDD event might be interpreted by the transport of seeds or stolons in mud on the feet of aquatic birds, and It has been considered a credible explanation for the LDD of aquatic groups [4, 17]. The geographic isolation between Eurasia and America likely contributed to the isolation of Limnobium. Although the phylogeny and biogeographic history of Hydrocharis has been greatly improved here, it should be mentioned that the incomplete sampling of Limnobium in America and only one individual was used for each species. There is still a need to include $L$. spongia and more populations to solve a more detailed biogeographic history of Hydrocharis.

\section{Methods}

\section{Taxon sampling and DNA extraction}

All the samples used in this study were listed in Table 1. The fresh leaves of two Hydrocharis species, H. chevalieri and H. dubia, were collected in 2019 from Cameroon and China, respectively. Limnobium laevigatum was sampled from a small swamp in Brazil. The field collection followed the ethics and legality of the local government and was permitted by the government. Total genomic DNA of these three species was extracted from silica-dried leaves using the MagicMag Genomic DNA Micro Kit (Sangon Biotech, Shanghai, China) following the manufacturer's protocol. The genomic DNA of $H$. morsus-ranae was retrieved from the Kew DNA bank (ID: 14513) and used for the subsequent analysis.

\section{Genome skimming, plastome assembly, and annotation}

The construction of all sequencing libraries and genome skimming was carried out following $\mathrm{Li}$ et al. [17]. Approximately $8.5 \mathrm{G}$ paired-end reads ( $150 \mathrm{bp}$ ) were yielded for each sample. After trimming and filtering using Fastp v. 0.20.0 [51] with default parameters, at least $7 \mathrm{G}$ clean reads were obtained. The complete plastomes were assembled de novo using GetOrganelle v. 1.7.5 with the recommended settings [52]. Web applications Geseq [53] and PGA [54] were applied to annotate genes in the newly generated plastomes using default settings, with manual adjustment of the start/stop codons through comparison with a reference plastome (Ottelia alismoides; NC_057494). Circular maps of plastome were created using OGDRAW v1.3.1 [55]. All newly generated sequencing data and annotated plastomes were submitted to the GenBank (Table 1).

\section{Comparative analysis and divergence hotspot identification}

The web-based software mVISTA [56] was used to identify the sequence and structural variations in Hydrocharis and Limnobium, using the plastome of $H$. dubia as reference. The comparison of expansions/contraction of IR in Hydrocharis and Limnobium was conducted using Geneious v 5.6.3 [57].

All the protein coding genes (PCGs) and intergenic spacers (IGSs) were extracted separately, and aligned in MAFFT v. 7.221 [58] with default settings. The program DnaSP v.6 [59] was used to assess the nucleotide diversity (Pi) for all PCGs and IGS of the studied plastomes. Additionally, the online application MISA [60] was employed to predict the simple sequence repeats (SSRs) for each 
plastome. The minimum number of repetitions was set to $10,5,4,3,3$, and 3, for mono-, di-, tri-, tetra-, penta-, and hexanucleotides, respectively. Furthermore, we explored the forward, reverse, palindromic, and complementary repeats for each plastome using REPuter web-based tools [61], with a minimum repeat size of $30 \mathrm{bp}$ and Hamming distance equal to 3 .

\section{Phylogenetic analysis}

Six plastomes of Hydrocharitaceae (Elodea canadensis NC_018541; Enhalus acoroides NC_048519; Halophila beccarii NC_051970; Najas flexilis NC_021936; Ottelia cordata NC_046891; Thalassia hemprichii NC_043774) were downloaded from GenBank. The PCGs were extracted from each of the plastomes and used in the phylogenetic analysis. A total of 78 PCGs in 15 Hydrocharitaceae species, three Alismataceae species (Alisma triviale, Baldellia ranunculoides, and Hydrocleys nymphoides), and Butomus umbellatus representing Butomaceae were retrieved from Ross et al. [7]. Finally, we compiled all 78 PCGs from 29 samples for our phylogenetic analysis (Table S2). Three Alismataceae species and B. umbellatus were used as outgroups.

All PCGs were aligned using MAFFT v. 7.221 [58] and ambiguously aligned regions were removed using trimAl v. 1.2 [62]. Unpartitioned and partitioned strategies of both Maximum likelihood (ML) and Bayesian inference (BI) methods were utilized for phylogenetic inference. For the unpartitioned strategy, we concatenated all 78 PCGs sequences as a supermatrix to infer the phylogenetic relationship with the best-fit model of nucleotide substitution estimated by ModelFinder [63]. For partitioned strategy, PartitionFinder 2 [64] was used to select the best-fit partitioning schemes and models for 78 PCGs via the rcluster algorithm. All phylogenetic analyses were performed with ML using IQ-Tree v. 1.6.12 [65] and BI using MrBayes v. 3.2.7 [66]. An ultrafast bootstrap approximation was used to estimate ML branch support values with 1000 replicates. BI was run using two independent runs of 8 million generations, and four Markov chains were set for each run, sampling trees every 5000 generations. After verifying that an average standard deviation of split frequencies was less than 0.001 , the initial $25 \%$ of the trees were discarded as burn-in. A consensus tree with Bayesian posterior probabilities (PP) was constructed from the remaining trees.

\section{Molecular dating and ancestral area reconstruction}

Three credible fossils from Hydrocharitaceae with Lognormal prior distributions were employed to calibrate the divergence times of the lineages within Hydrocharitaceae, following previous studies [4, 17, 67]. The first calibration point was assigned between Stratiotes and the rest of the Hydrocharitaceae based on the fossil seeds of Stratiotes from the Paleocene-Eocene boundary [67]. This node was constrained to a minimum of $54.5 \mathrm{Ma}$ (offset $=54.5$, mean $=1.0, \mathrm{SD}=1.0$ ). The fossil Thalas sites was applied to constrain the stem node of Enhalus + Halophila + Thalassia to the Middle Eocene. Thus, the split between (Enhalus + Halophila + Thalassia) and (Nechamandra + Vallisneria) was constrained to a minimum of $38.0 \mathrm{Ma}$ (offset $=38.0$, mean $=0.8, \mathrm{SD}=0.9$ ). The oldest fossil from Ottelia recorded in the Upper Eocene was used to constrain the split between Blyxa and Ottelia with a minimum age of $33.7 \mathrm{Ma}$ (offset $=33.7$, mean $=1.1, \quad \mathrm{SD}=1.2)$. An uncorrelated Lognormal relaxed clock model with Yule tree prior was applied for molecular dating implemented in BEAST v.1.10.4 [68]. We ran $8.0 \times 10^{8}$ iterations of Markov chain Monte Carlo (MCMC) and sampled every 2000 iterations. The program Tracer v. 1.7.1 [69] was used to check the effective sample size (ESS) for the convergence of each parameter discarding the initial $25 \%$ generations as burn-in.

According to the existing distribution patterns of Hydrocharis [1, 3], four major areas were identified for biogeographic analysis: A) East and Southeast Asia; B) Europe and Central Asia; C) Central Africa; D) America. The ancestral states were reconstructed using the BioGeoBEARS package [70] implemented in RASP v. 4.0 [19]. The best fit biogeographic model was selected by BioGeoBEARS [70] based on the Akaike Information Criterion cumulative weight (AICc_wt). The condensed tree and 100,000 sampled trees from BEAST analysis were used as input.

\section{Conclusion}

In this study, we firstly assembled plastomes of three Hydrocharis species and Limnobium laevigatum. Our phylogenomic analysis recovered non-monophyletic Hydrocharis and fully supported $H$. chevalieri as a sister to the rest of the species within the (Hydrocharis + Limnobium) group. Based on the morphological and phylogenomic evidence, we suggested treating Limnobium as the synonym of Hydrocharis. Moreover, we reappraised the divergence time and historical biogeography of Hydrocharis. Hydrocharis mainly diversified in the Miocene, rapid climate change during the Miocene may have contributed to the speciation of Hydrocharis and extinctions. The American members of the genus, i.e. former Limnobium, probably have dispersed to America through the Bering Land Bridge during the Miocene. In summary, our study provides new insights into the plastome evolution, phylogeny, and biogeography of the genus Hydrocharis. 


\section{Abbreviations}

AICc_wt: Akaike Information Criterion cumulative weight; BI: Bayesian inference; bp: Base pair; BS: Bootstrap; ESS: Effective sample size; IGSs: Intergenic spacers; IR: Inverted repeat; ITS: Internal transcribed spacer; LDD: Long distance dispersal; LSC: Large single copy; MCMC: Markov chain Monte Carlo; ML: Maximum Likelihood; MRCA: Most recent common ancestor; PCGs: Protein coding genes; Pi: Nucleotide diversity; PP: Posterior probability; rRNA: Ribosomal RNA; SSC: Small single copy; SSR: Simple sequence repeat; tRNA: Transfer RNA.

\section{Supplementary Information}

The online version contains supplementary material available at https://doi. org/10.1186/s12870-022-03483-2.

Additional file 1: Figure S1. Genome alignment of plastomes of Hydrocharis species and Limnobium laevigatum. H. dubia was used as a reference.

Additional file 2: Figure S2. Nucleotide diversity hotspot regions in plastomes of Hydrocharis species and Limnobium laevigatum.

Additional file 3: Figure S3. Analysis of repeat sequences in plastomes of Hydrocharis species and Limnobium laevigatum. (A) Total number of four repeat types. (B) Number of repeats divided by size.

Additional file 4: Table S1. Distribution of SSRs in plastomes of Hydrocharis species and Limnobium laevigatum.

Additional file 5: Table S2. List of the species downloaded from GenBank and Ross et al. (2016) used for phylogenomic and dating analyses in this study.

\section{Acknowledgments}

We are grateful to Rosie Woods for help in the DNA collection of Hydrocharis morsus-ranae. We appreciate three anonymous reviewers for their valuable suggestions to improve the manuscript. This research was conducted under Permit No. 0000072/MINRESI/B00/C00/C10/C12 in Cameroon. Permission for sampling Limnobium laevigata was issued by the Brazilian Ministry of Environment (ICMBIO/SISBIO 67605-2) and the shipment to Wuhan Botanical Garden was registered in Brazilian SISGEN platform (No. RF546AF).

\section{Authors' contributions}

Z-Z L, Q-FW, and J-M C conceived and designed the study. Z-Z L, AWG and SL performed de novo assembly, genome annotation, phylogenetic and other analyses. Z-Z L drafted the manuscript. Z-Z L, KM, J-MC collected the leaf materials. Z-Z L, AWG, and SL, EA revised the manuscript. All authors approved the final manuscript.

\section{Funding}

This work was supported by grants from the Strategic Priority Research Program of the Chinese Academy of Sciences (No. XDB31000000) and the National Natural Science Foundation of China (Nos. 32100186, 32070231).

\section{Availability of data and materials}

All newly annotated plastomes in this study are available from the National Center for Biotechnology Information (NCBI) (accession numbers: OK326868- OK326871). The associated BioProject, BioSample numbers, and SRA are PRJNA771243, SAMN22263148-SAMN22263151, and SRR16469678- SRR16469681.

\section{Declarations}

\section{Ethics approval and consent to participate}

Not applicable.

\section{Consent for publication}

Not applicable.

\section{Competing interests}

The authors declare that they have no competing interests.

\section{Author details}

${ }^{1}$ Key Laboratory of Aquatic Botany and Watershed Ecology, Wuhan Botanical Garden, Chinese Academy of Sciences, Wuhan 430074, China. ${ }^{2}$ Center of Conservation Biology, Core Botanical Gardens, Chinese Academy of Sciences, Wuhan 430074, China. ${ }^{3}$ Herbarium, Biodiversity Unit, University of Turku, 20014 Turku, Finland. ${ }^{5}$ Sino-Africa Joint Research Center, Chinese Academy of Sciences, Wuhan 430074, China. ${ }^{5}$ Departamento de Biologia, Universidade Federal de São Carlos, Sorocaba 18052-780, Brazil. ${ }^{6}$ Research Center of Fundamental and Applied Problems of Bioecology and Biotechnology of Ulyanovsk State Pedagogical University, 4/5, Lenin Square, 432071 Ulyanovsk, Russia.

Received: 27 October 2021 Accepted: 18 February 2022

Published online: 08 March 2022

\section{References}

1. Cook CDK, Lüönd R. A revision of the genus Hydrocharis (Hydrocharitaceae). Aquat Bot. 1982;14:177-204.

2. Bean AR. Hydrocharis dubia (Blume) backer (Hydrocharitaceae) is an alien species in Australia. Austrobaileya. 2011:8:435-7.

3. Efremov AN, Grishina VS, Kislov DE, Mesterházy A, Toma C. The genus Hydrocharis L. (Hydrocharitaceae): distribution features and conservation status. Bot Pac. 2020;9:83-94.

4. Chen LY, Chen JM, Gituru R, Wang QF. Generic phylogeny, historical biogeography and character evolution of the cosmopolitan aquatic plant family Hydrocharitaceae. BMC Evol Biol. 2012;12:30.

5. Polechońska L, Klink A. Validation of Hydrocharis morsus-ranae as a possible bioindicator of trace element pollution in freshwaters using Ceratophyllum demersum as a reference species. Environ Pollut. 2021;269:116145.

6. Cook CDK, Urmi-König K. A revision of the genus Limnobium including Hydromistria (Hydrocharitaceae). Aquat Bot. 1983;17:1-27.

7. Ross TG, Barrett CF, Soto-Gomez M, Lam VKY, Henriquez CL, Les DH, et al. Plastid phylogenomics and molecular evolution of Alismatales. Cladistics. 2016;32:160-78.

8. Bernardini B, Lucchese F. New phylogenetic insights into Hydrocharitaceae. Ann Bot. 2018;8:45-58.

9. Shaffer-Feher M. The endotegmen tuberculae: an account of little-known structures from the seed coat of the Hydrocharitoideae (Hydrocharitaceae) and Najas (Najadaceae). Bot J Linn Soc. 1991;107:169-88.

10. Les $\mathrm{DH}$, Moody ML, Soros CL. A reappraisal of phylogenetic relationships in the monocotyledon family Hydrocharitaceae (Alismatidae). Aliso. 2006;22:211-30.

11. Gateway P. A practical Flora to vascular plant species of the world. Vol. 4 of The Global Flora. Special ed. Bradford: GLOVAP, Nomenclature, Part 1; 2018.

12. Mai DH, Walther H. Die pliozänen Floren von Thü ringen. Quartärpaläontologie. 1988;7:55-295.

13. Carrión JS, Dupré M. Late Quaternary vegetational history at Navarrés, eastern Spain. A two-core approach. New Phytol. 1996;134:177-91.

14. Velichkevich FY, Zastawniak E. The Pliocene flora of Kholmech, SouthEastern Belarus and its correlation with other Pliocene floras of Europe. Acta Palaeobot. 2003;43:137-259.

15. Yao YF, Bruch AA, Mosbrugger V, Li CS. Quantitative reconstruction of Miocene climate patterns and evolution in southern China based on plant fossils. Palaeogeogr Palaeoclimatol Palaeoecol. 2011;304:291-307.

16. Li P, Lu RS, Xu WQ, Ohi-Toma T, Cai MQ, Qiu YX, et al. Comparative genomics and phylogenomics of east Asian tulips (Amana, Liliaceae). Front Plant Sci. 2017;8:1-12.

17. Li ZZ, Lehtonen S, Martins K, Gichira AW, Wu S, Li W, et al. Phylogenomics of the aquatic plant genus Ottelia (Hydrocharitaceae ): implications for historical biogeography. Mol Phylogenet Evol. 2020;152:106939.

18. Gichira AW, Chen LY, Li ZZ, Hu GW, Saina JK, Gituru RW, et al. Plastid phylogenomics and insights into the inter-mountain dispersal of the eastern African giant senecios (Dendrosenecio, Asteraceae). Mol Phylogenet Evol. 2021;164(11):107271.

19. Yu Y, Blair C, He XJ. RASP 4: ancestral state reconstruction tool for multiple genes and characters. Mol Biol Evol. 2020;37:604-6. 
20. Mwanzia VM, Nzei JM, Yan DY, Kamau PW, Chen JM, Li ZZ. The complete chloroplast genomes of two species in threatened monocot genus Caldesia in China. Genetica. 2019;147:381-90.

21. Ravi V, Khurana JP, Tyagi AK, Khurana P. An update on chloroplast genomes. Plant Syst Evol. 2008;271:101-22.

22. Wicke S, Schneeweiss GM, dePamphilis CW, Müller KF, Quandt D. The evolution of the plastid chromosome in land plants: gene content, gene order, gene function. Plant Mol Biol. 2011;76:273-97.

23. Jansen RK, Ruhlman TA. Plastid Genomes of Seed Plants. In: In Genomics of Chloroplasts and Mitochondria. Dordrecht: Springer; 2012. p. 103-26.

24. Mower JP, Vickrey TL. Structural diversity among plastid genomes of land plants. Adv Bot Res. 2018;85:263-92.

25. Jansen RK, Cai Z, Raubeson LA, Daniell H, dePamphilis CW, Leebens-Mack J, et al. Analysis of 81 genes from 64 plastid genomes resolves relationships in angiosperms and identifies genome-scale evolutionary patterns. Proc Natl Acad Sci U S A. 2007;104:19369-74.

26. Ruhlman TA, Jansen RK. The plastid genomes of flowering plants. In: Maliga $\mathrm{P}$, editor. Chloroplast biotechnology, methods in molecular biology (methods and protocols), vol. 1132. Totowa, NJ: Humana Press; 2014. p. 3 e38.

27. Schmickl R, Liston A, Zeisek V, Oberlander K, Weitemier K, Straub SCK, et al. Phylogenetic marker development for target enrichment from transcriptome and genome skim data: the pipeline and its application in southern African Oxalis (Oxalidaceae). Mol Ecol Resour. 2015;16:1124-35.

28. Li X, Zhao Y, Tu X, Li C, Zhu Y, Zhong H, et al. Comparative analysis of plastomes in Oxalidaceae: phylogenetic relationships and potential molecular markers. Plant Divers. 2021:43:281-91.

29. Bedoya AM, Ruhfel BR, Philbrick CT, Madriñán S, Bove CP, Mesterházy A, et al. Plastid genomes of five species of riverweeds (Podostemaceae): structural organization and comparative analysis in Malpighiales. Front Plant Sci. 2019;10:1-14.

30. Sudianto $E$, Chaw S. Two independent plastid $a c c D$ transfers to the nuclear genome of Gnetum and other insights on acetyl-CoA carboxylase evolution in gymnosperms. Genome Biol Evol. 2019;11:1691-705.

31. Zhu AD, Guo WH, Gupta S, Fan WS, Mower JP. Evolutionary dynamics of the plastid inverted repeat: the effects of expansion, contraction, and loss on substitution rates. New Phytol. 2016;209:1747-56.

32. Som A. Causes, consequences and solutions of phylogenetic incongruence. Brief Bioinform. 2015;16:536-48.

33. Weng ML, Blazier JC, Govindu M, Jansen RK. Reconstruction of the ancestral plastid genome in Geraniaceae reveals a correlation between genome rearrangements, repeats, and nucleotide substitution rates. Mol Biol Evol. 2014;31:645-59.

34. Provan J, Powell W, Hollingsworth PM. Chloroplast microsatellites: new tools for studies in plant ecology and evolution. Trends Ecol Evol. 2001;16:142-7.

35. Liu L, Wang Z, Huang L, Wang T, Su Y. Chloroplast population genetics reveals low levels of genetic variation and conformation to the centralmarginal hypothesis in Taxus wallichiana var. mairei, an endangered conifer endemic to China. Ecol Evol. 2019;9(20):11944-56.

36. Kosiński P, Sękiewicz K, Walas L, Boratyński A, Dering M. Spatial genetic structure of the endemic alpine plant Salix serpillifolia: genetic swamping on nunataks due to secondary colonization? Alp Bot. 2019;129(2):107-21.

37. Ren T, Yang Y, Zhou T, Liu ZL. Comparative plastid genomes of Primula species: sequence divergence and phylogenetic relationships. Int J Mol Sci. 2018;19:1050.

38. Stockey RA. The fossil record of basal monocots. Aliso. 2006;22:91-106.

39. Zachos J, Pagani H, Sloan L, Thomas E, Billups K. Trends, rhythms, and aberrations in global climate 65 ma to present. Science. 2001;292:686-93.

40. Kong H, Condamine FL, Harris AJ, Chen J, Pan B, Möller M, et al. Both temperature fluctuations and east Asian monsoons have driven plant diversification in the karst ecosystems from southern China. Mol Ecol. 2017;26:6414-29.

41. Crowley TJ, North GR. Abrupt climate change and extinction events in earth history. Science. 1988;240:996-1002.

42. Shukla A, Mehrotra RC, Guleria JS. Emergence and extinction of Dipterocarpaceae in western India with reference to climate change: fossil wood evidences. J Earth Syst Sci. 2013;122:1373-86.

43. Alçiçek H, Jiménez-Moreno G. Late Miocene to Plio-Pleistocene fluvio-lacustrine system in the Karacasu Basin (SW Anatolia, Turkey): depositional, paleogeographic and paleoclimatic implications. Sediment Geol. 2013;291:62-83.

44. Zhou Z, Hu JJ, Wen J, Sun H. Morphometric, phylogenetic and biogeographic analyses of Pyrularia (Santalales), a parasitic disjunct lineage between eastern Asia and eastern North America. Taxon. 2019;68:47-71.
45. Namgung J, Do HDK, Kim C, Choi HJ, Kim JH. Complete chloroplast genomes shed light on phylogenetic relationships, divergence time, and biogeography of Allioideae (Amaryllidaceae). Sci Rep. 2021;11:1-13.

46. Keeley SC, Cantley JT, Gallaher TJ. The "evil tribe" spreads across the land: a dated molecular phylogeny provides insight into dispersal, expansion , and biogeographic relationships within one of the largest tribes of the sunflower family (Vernonieae : Compositae). Am J Bot. 2021;108:505-19.

47. Tiffney BH, Manchester SR. The use of geological and paleontological evidence in evaluating plant phylogeographic hypotheses in the northern hemisphere tertiary. Int J Plant Sci. 2001;162:S3-S17.

48. Donoghue MJ, Smith SA. Patterns in the assembly of temperate forests around the northern hemisphere. Philos Trans R Soc Lond Ser B Biol Sci. 2004;2004(359):1633-44.

49. Jia LB, Manchester SR, Su T, Xing YW, Chen WY, Huang YJ, et al. First occurrence of Cedrelospermum (Ulmaceae) in Asia and its biogeographic implications. J Plant Res. 2015;128:747-61.

50. Marincovich L, Gladenkov AY. Evidence for an early opening of the Bering Strait. Nature. 1999;397:149-51.

51. Chen SF, Zhou YQ, Chen YR, Gu J. Fastp: an ultra-fast all-in-one FASTQ preprocessor. Bioinformatics. 2018;34:884-90.

52. Jin JJ, Yu WB, Yang JB, Song Y, dePamphilis CW, Yi TS, et al. GetOrganelle: a fast and versatile toolkit for accurate de novo assembly of organelle genomes. Genome Biol. 2020;21:241.

53. Tillich M, Lehwark P, Pellizzer T, Ulbricht-Jones ES, Fischer A, Bock R, et al. GeSeq-versatile and accurate annotation of organelle genomes. Nucleic Acids Res. 2017:45:6-11.

54. Qu XJ, Moore MJ, Li DZ, Yi TS. PGA: a software package for rapid, accurate, and flexible batch annotation of plastomes. Plant Methods. 2019;15:50.

55. Lohse M, Drechsel O, Kahlau S, Bock R. OrganellarGenomeDRAW — a suite of tools for generating physical maps of plastid and mitochondrial genomes and visualizing expression data sets. Nucleic Acids Res. 2013;41:W575-81.

56. Mayor C, Brudno M, Schwartz JR, Poliakov A, Rubin EM, Frazer KA, et al. VISTA: visualizing global DNA sequence alignments of arbitrary length. Bioinformatics. 2000;16:1046-7.

57. Kearse M, Moir R, Wilson A, Stones-Havas S, Cheung M, Sturrock S, et al. Geneious basic: an integrated and extendable desktop software platform for the organization and analysis of sequence data. Bioinformatics. 2012;28:1647-9.

58. Katoh K, Standley DM. MAFFT multiple sequence alignment software version 7: improvements in performance and usability. Mol Biol Evol. 2013;30:772-80.

59. Rozas J, Ferrer-Mata A, Sanchez-DelBarrio JC, Guirao-Rico S, Librado P, Ramos-Onsins SE, et al. DnaSP 6: DNA sequence polymorphism analysis of large data sets. Mol Biol Evol. 2017;34:3299-302.

60. Beier S, Thiel T, Münch T, Scholz U, Mascher M. MISA-web: a web server for microsatellite prediction. Bioinformatics. 2017;33:2583-5.

61. Kurtz S, Choudhuri JV, Ohlebusch E, Schleiermacher C, Stoye J, Giegerich R. REPuter: the manifold applications of repeat analysis on a genomic scale. Nucleic Acids Res. 2001;29:4633-42.

62. Capella-Gutierrez S, Silla-Martinez JM, Gabaldon T. trimAl: a tool for automated alignment trimming in large-scale phylogenetic analyses. Bioinformatics. 2009;25:1972-3.

63. Kalyaanamoorthy S, Minh BQ, Wong TKF, von Haeseler A, Jermiin LS. ModelFinder: fast model selection for accurate phylogenetic estimates. Nat Methods. 2017;14:587-9.

64. Lanfear R, Frandsen PB, Wright AM, Senfeld T, Calcott B. Partitionfinder 2: new methods for selecting partitioned models of evolution for molecular and morphological phylogenetic analyses. Mol Biol Evol. 2017;34:772-3.

65. Nguyen LT, Schmidt HA, von Haeseler A, Minh BQ. IQ-TREE: a fast and effective stochastic algorithm for estimating maximum-likelihood phylogenies. Mol Biol Evol. 2015;32:268-74.

66. Ronquist F, Teslenko M, van der Mark P, Ayres DL, Darling A, Höhna S, et al. MrBayes 3.2: efficient Bayesian phylogenetic inference and model choice across a large model space. Syst Biol. 2012;61:539-42.

67. Iles WJ, Smith SY, Gandolfo MA, Graham SW. Monocot fossils suitable for molecular dating analyses. Bot J Linn Soc. 2015;178:346-74.

68. Drummond AJ, Suchard MA, Xie D, Rambaut A. Bayesian phylogenetics with BEAUti and the BEAST 1.7. Mol Biol Evol. 2012;29:1969-73.

69. Rambaut A, Suchard MA, Xie D, Drummond AJ. Tracer v1.6. 2014. Available at: http://beast.bio.ed.ac.uk/Tracer. Accessed April 20, 2021. 
70. Matzke NJ. Model selection in historical biogeography reveals that founder-event speciation is a crucial process in island clades. Syst Biol. 2014;63:951-70

\section{Publisher's Note}

Springer Nature remains neutral with regard to jurisdictional claims in published maps and institutional affiliations.

- fast, convenient online submission

- thorough peer review by experienced researchers in your field

- rapid publication on acceptance

- support for research data, including large and complex data types

- gold Open Access which fosters wider collaboration and increased citations

- maximum visibility for your research: over $100 \mathrm{M}$ website views per year

At BMC, research is always in progress.

Learn more biomedcentral.com/submissions 